\title{
FAKTOR-FAKTOR YANG MEMPENGARUHI PENEGAKAN STANDAR DIAGNOSIS KEPERAWATAN DI RUMAH SAKIT UMUM DAERAH SOEDARSO PONTIANAK
}

\author{
Yohanes Ransan*, Ichsan Budiharto ${ }^{* *}$, Herman $* *$ \\ * Mahasiswa Program Studi Ilmu Keperawatan Universitas Tanjungpura \\ ** Dosen Program Studi Keperawatan Universitas Tanjungpura
}

\begin{abstract}
ABSTRAK
Latar Belakang: Diagnosis keperawatan harus ditingkatkan lagi didalam dipelayanan rumah sakit dan fasilitas kesehatan lainnya agar seragam, akurat, dan tidak ambigu. Penegakan diagnosis keperawatan sebagai salah satu komponen standar asuhan keperawatan perlu dilaksanakan dengan baik sebagaimana yang diamanahkan dalam undang-undang No.38 tahun 2014 tantang keperawatan pada pasal 30 bahwa dalam menjalankan tugas sebagai pemberi asuhan keperawatan, perawat berwenang menetapkan diagnosis keperawatan. Perawat sebagai penegak diagnosis yang harus memiliki kemampuan diagnosis yang baik sebagai dasar mengembangkan rencana intervesnsi keperawatan dalam mencapai peningkatan, pencegahan, penyembuhan dan pemulihan kesehatan klien.

Tujuan: Untuk mengetahui factor-faktor yang mempengaruhi penegakan standar diagnosis keperawatan di RSUD Soedarso Pontianak.

Metode: Penelitian kuantitatif dengan rancangan cross sectional. Jumlah sampel 77 responden menggunakan teknik probability sampling dengan metode pengambilan sampel stratified random sampling. Analisa data menggunakan uji chi square.

Hasil: Uji statistik dengan uji chi square factor usia, pendidikan, masa kerja diperoleh hasil nilai $\mathrm{p}>0,05$ yang artinya $\mathrm{H}_{0}$ diterima dan motivasi perawat diperoleh hasil $\mathrm{p}=0,036$ $(<0,05)$ yang artinya Ha ditolak.

Kesimpulan: Tidak terdapat hubungan antara usia, pendidikan, dan masa kerja terhadap penegakan diagnosis keperawatan dan terdapat hubungan motivasi perawat terhadap penegakan diagnosis keperawatan di ruang rawat inap di RSUD Soedarso Pontianak.
\end{abstract}

Kata Kunci :Penegakan Diagnosa. Diagnosis Keperawatan. 


\title{
THE FACTORS AFFECTING THE ENFORCEMENT OF NURSING DIAGNOSIS STANDARDS IN SOEDARSO REGIONAL HOSPITAL IN PONTIANAK
}

\author{
Yohanes Ransan*, Ichsan Budiharto $*$ * Herman ** \\ * Nursing Student Tanjungpura University \\ ** Nursing Lecture Tanjungpura University
}

\begin{abstract}
Background: Nursing diagnoses must be further improved in providing hospital services and other health facilities so that they are consistent, accurate, and unambiguous. The enforcement of nursing diagnoses is perceived as one component of the standard of nursing care needs to be carried out properly as mandated in law No. 38 of 2014 concerning nursing. In article 30 of this law, it is stated that nurses are authorized to determine nursing diagnoses in carrying out their duties as providers of nursing care. The nurse as a diagnosis enforcer must have good diagnosis skills as a basis for developing a nursing intervention plan in achieving improvement, prevention, healing, and recovery of the client's health.

Objective: To identify the factors that influence the establishment of nursing diagnosis standards at Soedarso Regional Hospital Pontianak.

Method: The researcher used quantitative research methods with a crosssectional design. A total of 77 respondents were selected as the research sample using a probability sampling technique with the stratified random sampling method. In this study, the researcher also used the chi-square test to analyze data..

Research Findings: From the statistical test with the chi-square test of the factors of age, education and years of service, the research findings were revealed in the form of $p<0.05$, which means that $\mathrm{HO}$ was accepted. On the other hand, from the motivation results of nurses, the results obtained $p=0.036(<0.05)$ which means that Ha was rejected.

Conclusion: There is no correlation between age, education, and years of service on establishing a nursing diagnosis. However, there is a link between nurses' motivation and nursing diagnoses in the inpatient room at Soedarso Regional Hospital Pontianak.
\end{abstract}

Keywords: Enforcement of the Diagnosis, Nursing Diagnosis 


\section{PENDAHULUAN}

Diagnosis

keperawatan

merupakan penilaian klinis terhadap pengalaman atau respon individu, keluarga, dan komunitas pada masalah kesehatan pada resiko masalah kesehatan atau pada proses kehidupan. Diagnosis keperawatan merupakan bagian vital dalam menentukan asuhan keperawatan yang sesuai untuk membantu klien mencapai kesehatan yang optimal. Mengingat pentingnya diagnosis keperawatan dalam memberian asuhan keperawatan, maka dibutuhkan standar diagnosis keperawatan yang dapat diterapkan di indonesia $^{[1]}$.

\section{Penegakan}

diagnosis

keperawatan sebagai salah satu komponen standar asuhan keperawatan perlu dilaksanakan dengan baik sebagaimana yang diamanahkan dalam undang-undang No.38 tahun 2014 tantang keperawatan pada pasal 30 bahwa dalam menjalankan tugas sebagai pemberi asuhan keperawatan, perawat berwenang menetapkan diagnosis keperawatan. Hal ini menegaskan wewenang perawat sebagai penegak diagnosis yang harus memiliki kemampuan diagnosis yang baik sebagai dasar mengembangkan rencana intervensi keperawatan dalam rangka mencapai peningkatan, pencegahan dan penyembuhan serta pemulihan kesehatan klien ${ }^{[1]}$.

Sebuah studi yang dilakukan di Indonesia menunjukkan bahwa 50\% bentuk penilaian keperawatan tidak mengandung informasi lengkap ${ }^{[2]}$. Sebagian besar dokumen proses keperawatan tidak lengkap, karena persepsi bahwa formulir keperawatan tidak sesuai untuk mendokumentasi kan kebutuhan perawatan pasien. melaporkan bahwa proses dokumentasi tidak mampu menangkap informasi dari diagnosis keperawatan. Studi ini menunjukkan bahwa sedikit atau tidak ada usaha yang dilakukan untuk mengabungkan formulir penilaian dengan diagnosis keperawatan, serta penerapan diagnosis keperawatan di Indonesia.

Dokumentasi keperawatan menyita hampir $50 \%$ waktu perawat pershift kebanyakan perawat dalam urutan klinis, tidak melakukan 
dokumentasi yang lengkap. Alasan mengapa perawat tidak melakukan dokumentasi keperawatan adalah kebanyakan perawat lebih memilih meluangkan waktu untuk melakukan tindakan pada pasien dan tidak mendokumentasikannya. Faktor pekerjaan, pelatihan dan beban kerja. Merupakan faktor yang dapat mempengaruhi kelengkapan dokumentasi keperawatan. Lingkungan kerja, beban kerja yang tinggi, dan sulitnya dokumentasi format waktu pengisian berkontribusi terhadap kurangnya dokumentasi keperawatan $^{[3]}$.

\begin{tabular}{ll}
\multicolumn{2}{c}{ Berdasarkan hasil studi } \\
pendahuluan yang dilakukan di
\end{tabular}
Ruang Rawat Inap L, K, G, dan F RSUD Soedarso Pontianak. Dari hasil wawancara kepada beberapa perawat di Ruang rawat inap mengatakan cara menegakan diagnosis keperawatan dengan cara melakukan pengkajian, pemeriksaan fisik, pemeriksaan penunjang, data subjektif, dan data objektif. Pada saat melihat rekam medik yang sudah terisi oleh perawat ruangan serta saat peneliti melakukan observasi terdapat ketidak cocokan data yang diambil dengan hasil wawancara perawat ruangan yang menyatakan bahwa diruangan tersebut sering mengangkat diagnosa nyeri yang dialami pasien nyeri yang berat sedangkan ketika peneliti observasi pada pasien diruangan tersebut, didapatkan diagnosa nyeri sering digunakan pada pasien namun tingkat nyeri yang dialami pasien adalah tingkat nyeri ringan dan tanda minor yang muncul hanya dua sampai tiga. Sehingga data yang didapat kurang menunjang dalam penegakan diagnosis, semua diagnosis yang dibuat oleh perawat terlihat sama dan tidak sesuai dengan hasil pengkajian. Berdasarkan latar belakang yang peneliti uraikan, peneliti tertarik untuk meneliti mengenai faktor-faktor yang mempengaruhi penegakan standar diagnosis keperawatan di RSUD Soedarso Pontianak. 


\section{METODE}

Penelitian ini termasuk jenis penelitian kuantitatif dengan metode deskriptif yaitu suatu penelitian yang bertujuan menggambarkan suatu penelitian (deskripsi) tentang keadaan tertentu secara objektif ${ }^{[4]}$ dengan pendekatan cross sectional yaitu sebuah penelitian yang menekankan waktu observasi atau pengukuran data dari variabel independen dan dipenden hanya satu kali atau sekaligus dalam satu waktu $^{[5]}$.

Populasi dalam penelitian ini adalah semua perawat yang berkerja di ruang rawat inap di RSUD Soedarso Pontianak yang meliputi perawat di ruang $\mathrm{K}, \mathrm{L}, \mathrm{F}, \mathrm{H}, \mathrm{G}$ yang berjumlah 96 orang. Sampel yang didapatka berjumlah 77 orang dengan mengunakan perhitungan Swarjana . Teknik sampling yang digunakan dalam penelitian ini yaitu Simpel random sampling dengan metode pengambilan sempel secara acak sederhana dan setiap individu memiliki peluang yang sama untuk menjadi responden dengan metode pengambilan sampel stratified random sampling untuk mempertimbangkan stratifikasi atau strata dalam populasi sehingga setiap strata terwakili untuk menjadi sampel $^{[6]}$.

Instrumen yang digunakan dalam penelitian ini yaitu Kuesioner Diagnosis Keperawatan yang berisi 14 pernyataan, dan Kuesioner Karakterristik perawat dalam 3 pernyataan. Kuesioner ini dilakukan uji validitas di Ruang C Rawat inap RSUD Soedarso Pontianak dan Kuesioner Motivasi Kerja yang berisikan 21 pernyataan.

Penelitian ini telah dilakukan di RSUD Soedarso Pontianak diruang rawat inap, $\mathrm{K}, \mathrm{L}, \mathrm{F}, \mathrm{H}$, dan $\mathrm{G}$ selama 18 hari yaitu dimulai pada tanggal 20 September-7 Oktober 2018. 
HASIL

Tabel 1 Distribusi Reponden berdasarkan karakteristik individu $(\mathrm{N}=77)$

\begin{tabular}{|c|c|c|}
\hline $\begin{array}{l}\text { Karakteristik } \\
\text { Responden }\end{array}$ & $\boldsymbol{F}$ & $\%$ \\
\hline \multicolumn{3}{|l|}{ Usia } \\
\hline 17-25 tahun & 32 & 41,6 \\
\hline 26-35 tahun & 45 & 58,4 \\
\hline \multicolumn{3}{|l|}{ Jenis kelamin } \\
\hline Laki-laki & 22 & 28,6 \\
\hline Perempuan & 55 & 71,4 \\
\hline \multicolumn{3}{|l|}{ Pendidikan } \\
\hline D III & 59 & 76,6 \\
\hline S1 & 18 & 23,4 \\
\hline \multicolumn{3}{|l|}{ Masa kerja } \\
\hline $1-5$ tahun & 31 & 40,3 \\
\hline$>5$ tahun & 46 & 59,7 \\
\hline \multicolumn{3}{|l|}{ Motivasi } \\
\hline Tinggi & 62 & 80,5 \\
\hline Rendah & 15 & 19,5 \\
\hline \multicolumn{3}{|c|}{ Status kepegawaian } \\
\hline PNS & 41 & 53,2 \\
\hline Magang & 36 & 46,8 \\
\hline
\end{tabular}

Sumber : Data Primer (2018), telah diolah

Berdasarkan data pada tabel 1 didapatkan hasil usia perawat terbanyak yaitu pada rentang 26-36 tahun sebesar 58,4\%. Karakteristik jenis kelamin didapatkan hasil perempuan menjadi jenis kelamin terbanyak yaitu $71,4 \%$. Karakteristik jenis pendidikan didapatkan hasil DIII menjadi jenis pendidikan yang terbanyak yaitu $76,6 \%$. Karakteristik masa bekerja terbanyak yaitu pada rentang 1-5 tahun sebanyak $40,3 \%$. Karakteristik motivasi terbanyak yaitu pada motivasi tinggi sebanyak 80,5\%. Karakteristik status kepegawaian didapatkan hasil terbanyak yaitu pada perawat PNS sebanyak $53,2 \%$.

Tabel 2 Distribusi Diagnosa Keperawatan (N=77

\begin{tabular}{ccc}
\hline Kategori & F & $\%$ \\
\hline Baik & 75 & 97,4 \\
Buruk & 2 & 2,6
\end{tabular}

Sumber : Data Primer (2018), telah diolah Berdasarkan tabel 2 didapatkan hasil diagnosa keperawatan pada ruangan rawat inap dalam kategori baik yaitu sebanyak $(97,4 \%)$ sedangkan yang buruk sebanyak $(2,6 \%)$. 
Tabel 3 Pengaruh Faktor Usia,

Pendidikan, Masa Kerja, Motivasi,

Terhadap Penegakan Standar Diagnosa

Keperawatan $(\mathrm{N}=77)$

\begin{tabular}{llcccc}
\hline $\begin{array}{l}\text { Diagnosa } \\
\text { keperawatan }\end{array}$ & Baik & Buruk & \\
\hline & $\boldsymbol{F}$ & $\%$ & $\boldsymbol{F}$ & $\%$ & \\
\hline Usia & & & & & \\
17-25 tahun & 32 & 42,7 & 0 & 0 & 0,508 \\
26-36 tahun & 43 & 57,3 & 2 & 100 & \\
\hline
\end{tabular}

Pendidikan

$\begin{array}{llllll}\mathrm{S} 1 & 18 & 24,0 & 0 & 0 & 1,000\end{array}$

D III

$\begin{array}{llll}57 & 76,0 \quad 2 & 100\end{array}$

\begin{tabular}{llllll}
\hline Masa kerja & & & & & \\
$1-5$ tahun & 31 & 41,3 & 0 & 0 & 0,513 \\
$>5$ tahun & 44 & 58,7 & 2 & 100 & \\
\hline Motivasi & & & & & \\
Tinggi & 62 & 82,7 & 0 & 0 & 0,036 \\
Rendah & 13 & 17,3 & 2 & 100 & \\
\hline
\end{tabular}

Sumber : Data Primer (2018), telah diolah

Berdasarkan tabel 3

didapatkan hasil bahwa usia, pendidikan, dan masa kerja tidak ada hubungan dengan penegakan diagnosa keperawatan.

Sedangkan motivasi terdapat hubungan dengan penegakan diangnosa keperawat dengan hasil uji chi square didapatkan nilai $\mathrm{p}=0,036$.

\section{Karakteristik Responden}

\section{Berdasarkan Usia}

Pada usia ini kematangan diri seseorang mulai mencapai puncaknya dan pada usia ini juga seseorang masuk kedalam usia yang tergolong produktif. dimana semakin matang usia seseorang maka kemampuan seseorang dalam berpikir dan bekerja semakin matang pula sehingga orang yang lebih cukup umurnya cenderung lebih dipercaya karena tentu memiliki pengalaman yang lebih dari pada orang yang masih berusia awal ${ }^{[8]}$.

Penelitian lain yang mendukung pernyataan ini yaitu penelitian yang dilakukan oleh ${ }^{[9]}$ yang menyatakan bahwa sesorang yang berada pada usia produktif cenderung memiliki motivasi dan semangat kerja yang tinggi akan berdampak pada kinerja yang baik.

Pada umumnya usia yang lebih muda memiliki sikap yang kurang dalam bekerja, sedangkan seseorang yang lebih dewasa cenderung memiliki komitmen yang tinggi dalam bekerja ${ }^{[9]}$. Hal ini juga 
terjadi pada usia > 40 tahun dimana seseorang mulai memasuki usia dewasa akhir dimana produktifitasnya menurun yang berdampak pada kecepatan, kecekatan dan ketelitian dalam bekerja $^{[10] .}$ Untuk itu banyaknya perawat yang berusia dewasa awal diharapkan pula dapat memberi dorongan kepada perawat yang berusia remaja akhir untuk lebih giat lagi melaksanakan proses keperawatan salah satunya melakukan penegakan diagnosa keperawatan yang lebih efektif ${ }^{[9]}$.

Dari hasil distribusi data dalam penelitian ini didapatkan hasil rata-rata usia perawat 30 tahun atau masih termasuk dalam kategori usia muda. Hal ini tentu sangat menguntungkan pihak rumah sakit terkhusus didalam bidang SDM dimana pada usia tersebut tenaga perawat dalam kondisi yang baik dan diharapkan usia muda ini dapat memberikan kinerja kerja yang baik pula $^{[11]}$.
Karakteristik

Responden

\section{Berdasarkan Jenis Kelamin}

Dikatakan bahwa perempuan cenderung memiliki kedisiplinan dan ketekunan tinggi dibandingkan lakilaki, hal ini akan berdampak pada perempuan akan memiliki sikap disiplin dan ketekunan yang tinggi pula dalam bekerja termasuk dalam melakukan penegakan diagnosa keperawatan dengan baik ${ }^{[12]}$.

Hampir disetiap ruangan wanita mendominasi dari pada lakilaki. Keperawatan sendiri lebih banyak diminati oleh perempuan karena pekerjaannya identik dengan sifat wanita yang lemah lembut dan memiliki sikap caring yang tinggi ${ }^{[13]}$. Hal ini juga mungkin didasari oleh pandangan orang bahwa perawat adalah pekerjaan perempuan dimana pada sejarah keperawatan masyarakat primitif, kata perawatan berawal dari bagaimana seorang perempuan yang merawat anak yang sedang tidak berdaya. Wanita juga berperan sebagai istri dan ibu yang memberikan perawatan dan pengasuhan didalam keluarganya dan keperawatan juga adalah sebuah 
pekerjaan yang didasari oleh kasih sayang seorang perempuan selain hampir seluruh perintis keperawatan adalah perempuan yang salah satunya Florence Nighttingale ${ }^{[14]}$.

Menyatakan yang jenis kelamin dapat menjadi faktor yang mempengaruhi kinerja kerja. Hampir 90\% keperawatan berisi kaum wanita yang diidentikan memiliki rasa sosial yang tinggi. Sikap ini sangat mempengaruhi ketika ia memberikan perawatan kepada pasien, kelompok serta masyarakat ${ }^{[15]}$.

Dalam penelitian ini juga didapatkan bahwa sekitar 71,4\% perempuan memiliki motivasi kerja yang tinggi, sedangkan pada laki-laki yang memiliki motivasi kerja tinggi sekitar 28,6\%. Hal ini bisa disebabkan karena perempuan memiliki tingkat kesabaran yang jauh lebih baik dan tinggi serta lebih mampu untuk menghadapi stres sehingga motivasi kerja yang perempuan miliki cukup tinggi ${ }^{[16]}$.

\section{Karakteristik}

Responden

\section{Berdasarkan Tingkat Pendidikan}

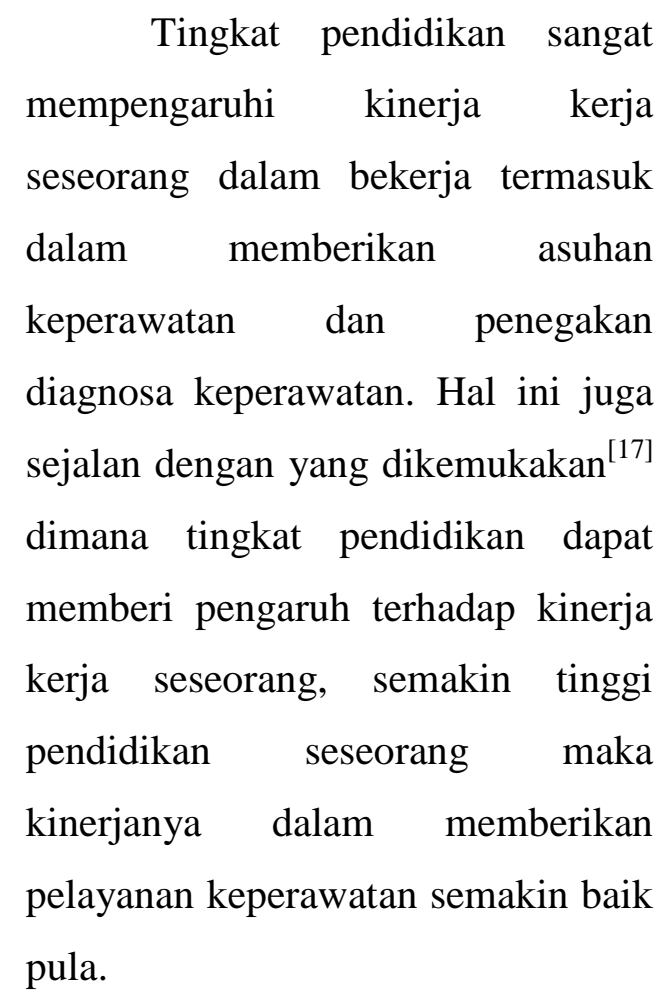

Pendidikan terakhir seseorang mempengaruhi tingkat kemampuan, pengetahuan dan semakin percaya diri untuk bekerja karena pendidikan sendiri penting untuk mengembangkan kemampuan seseorang $^{[18]}$.

\section{Karakteristik Responden}

Berdasarkan Masa Bekerja

Dari hasil penelitian

didapatkan 59,7\% perawat yang

memiliki masa kerja $>5$ tahun

memiliki motivasi kerja yang tinggi. 
Pada masa ini adalah waktu yang

cukup bagi perawat untuk bekerja

sehingga semangat bekerja masih

sangat tinggi karena pada masa ini

lah perawat masih mengasah

kemampuannya dalam bekerja.

Masa kerja yang lama akan membuat seseorang terbiasa dengan lingkungan kerja sehingga seseorang tersebut dapat merasa nyaman. karena adaptasi yang dirasa sangat cukup. Seseorang dengan masa kerja yang lama akan bekerja lebih efektif dan masalah yang datang akan mudah diatasi karena pengalaman dalam mengatasi kendala kerja sudah cukup. Semakin lama bekerja, keterampilan yang dimiliki juga meningkat sehingga diharapkan dengan pengalaman yang dirasa tidak terlalu awal dan tidak terlalu lama ini dapat memberikan kinerja yang efektif $^{[19]}$.

\section{Karakteristik}

Responden

\section{Berdasarkan Status Kepegawaian}

Pada penelitian ini didaptkan jumlah terbanyak adalah perawat yang berstatus PNS karena RSUD Soedarso sendiri adalah rumah sakit umum daerah pontianak sehingga pekerja PNS banyak ditemui di RSUD sendiri.

Dari hasil penelitian didapatkan pula 46,8\% Magang, dan $53,2 \%$ PNS yang memiliki motivasi kerja tinggi. Hal ini mungkin disebabkan karena PNS adalah status pekerjaan yang pasti sehingga lebih memiliki semangat bekerja yang tinggi. Pegawai PNS cenderung memiliki disiplin kerja yang tinggi dibandingkan pegawai non $\mathrm{PNS}^{[12]}$.

\section{Motivasi Kerja Perawat}

Motivasi adalah hal utama yang membuat seseorang bekerja dan melakukan semua tindakan dengan efektif dan motivasi kerjalah yang mengarahkan perilaku kepada arah yang baik maupun tidak dalam melakukan pekerjaannya. Perawat akan melaksanakan asuhan keperawatan dengan baik jika mempunyai keinginan dan dorongan untuk melakukan pekerjaan tersebut $^{[20]}$.

Hasil penelitian di RSUD Soedarso di dukung oleh penelitian yang dilakukan oleh ${ }^{[21]}$ di RSP yaitu sebanyak $55,6 \%$ perawat memiliki motivasi tinggi dan penelitian yang 
dilakukan oleh Darmayanti di RSUD Sultan Syarif Mohamad Alkadrie yaitu sebanyak $67,6 \%$ perawat memiliki motivasi tinggi.

Lebih dari separuh perawat dalam penelitian ini juga memiliki motivasi kerja tinggi karena didukung dengan tempat kerja yang menyenangkan, selalu berkomunikasi antar perawat serta atasan yang mau membantu saat perawat pelaksana mengalami kesusahan dalam bekerja serta adanya kemauan dari perawat untuk bekerja yang lebih baik lagi. perawat menyatakan $75 \%$ dukungan dari rekan kerja sangat mempengaruhi seseorang dalam melaksanakan pekerjaannya yang dilihat dari aspek kesedian dari rekan kerja membantu dalam melaksanakan asuhan keperawatan, pendokumentasian yang lengkap serta penyampaian informasi tentang pasien secara komprehensif saat serah terima pasien antar kedua shift jaga yang dibuktikan dengan ${ }^{[22]}$.

Gaji merupakan salah satu yang mempengaruhi kepuasan seseorang setelah selesai bekerja ${ }^{[20]}$.
Didalam proses motivasi ketika seseorang telah melakukan pekerjaannya maka ada 2 kemungkinan yang akan ia dapatkan. Apakah mendapat imbalan atau mendapat hukuman. Agar bisa mendapatkan imbalan, maka orang tersebut harus bekerja dengan sunggung-sungguh dan secara tidak langsung akan meningkatkan motivasi kerja dari orang tersebut ${ }^{[23]}$. Hal ini diperkuat oleh penelitian yang dilakukan oleh ${ }^{[24]}$ terdapat hubungan positif antara pemberian insentif terhadap motivasi kerja pegawai yang dalam arti pemberian bonus kepada pegawai sesuai dengan beban kerja masing-masing.

\section{Hubungan Faktor Usia Perawat dengan Penegakan Standar Diagnosa Keperawatan di Ruang Rawat Inap RSUD Soedarso Pontianak}

Menurut peneliti usia perawat yang berusia 17-25 tahun dan 26-35 sudah baik dalam melakukan penegakan diagnosa sehingga tidak ada perbedaan antara yang muda dengan tua. Dimana yang tua sudah berpengalaman sehingga tidak ada kesusahan dalam melakukan 
diagnosa sedangkan yang muda ilmu yang didapatkan lebih tinggi sehingga tidak megalami kesusahan dalam melakukan penegakan diagnosa keperawatan.

Usia sangat menentukan kedewasaan seseorang, karena semakin tinggi usia seseorang maka pengalaman seseorang juga akan tinggi pula. Orang yang dewasa maka akan memperlihatkan kematangan berfikir, dalam menelaah sesuatu dengan pikiran yang positif, sehingga responden yang berusia dewasa akhir akan memiliki pola pikir yang lebih dewasa dibandingkan dewasa awal. Pada penelitian ini seseorang yang berusia tua akan memiliki kematangan berfikir untuk pendokumentasian asuhan keperawatan yang dilakukannya pada setiap pasien yang ada diruangan sehingga tindakan yang diberikan tepat pada pasien. Seseorang yang memiliki usia muda akan senantiasa memberikan pendokumentasian yang lengkap, karena seorang yang berusia muda akan mudah untuk mengingat apa yang seharusnya akan ditulis dalam pendokumentasian yang dilakukan pada pasien yang berada diruangan $^{[25]}$.

\section{Hubungan Faktor Pendidikan \\ Perawat dengan Penegakan}

Standar Diagnosa Keperawatan di Ruang Rawat Inap RSUD Soedarso Pontianak

Perawat dengan tingkat pendidikan yang berbeda mempunyai kualitas dokumentasi yang dikerjakan berbeda pula karena semakin tinggi tingkat pendidikannya maka kemampuan secara kognitif dan keterampilan akan meningkat ${ }^{[5]}$.

Menurut peneliti pendidikan DIII dan S1 keperawatan sudah baik dan benar dalam melakukan penegakan diagnosa dimana pendidikan DIII dan S1 sama saja tidak ada perbedaan dalam melakukan penegakan diagnosa dimana yang DIII sudah sedikit tua dan pengalaman sudah banyak sehingga lebih mengerti sedangkan yang S1 banyak yang muda pengalaman masih kurang sehigga tidak ada pengaruh pendidikan dengan penegakan diagnosa keperawatan. 
Pendidikan yang tinggi akan mencerminkan

kemampuan

seseorang untuk dapat

menyelesaikan suatu pekerjaan dengan baik. Orang yang mempunyai pendidikan tinggi maka mempunyai pengalaman yang tinggi pula, dan memiliki pola pikir yang lebih matang sehingga bisa membedakan mana yang baik dan mana yang buruk. Pada penelitian ini terdapat orang yang memiliki pendidikan tinggi akan memberikan pendokumentasian yang lengkap pada asuhan keperawatan pasien yang berada diruangan. Orang yang mempunyai pendidikan tinggi akan memilikin pengalaman yang baik untuk pendokumentasian asuhan keperawatan pada pasien yang berada diruangan ${ }^{[25]}$.

Hubungan Faktor Masa Kerja Perawat dengan Penegakan Standar Diagnosa Keperawatan di Ruang Rawat Inap RSUD

\section{Soedarso Pontianak}

Semakin lama masa kerja maka karyawan akan menghasilkan produktifitas yang tinggi. Bertambahnya lama kerja seorang perawat sebaiknya disertai dengan kegiatan untuk meningkatkan keterampilan, pengetahuan, dan kemampuan setiap individu agar tidak terjadi kejenuhan terhadap rutinitas sehingga kualitas dokumentasi menjadi lebih baik ${ }^{[26]}$.

Menurut peneliti masa kerja perawat 1-5 tahun dan $>5$ tahun tidak berpengaruh terhadap penegakan diagnosa keperawatan dimana didapatkan didalam penelitian bahwa masa kerja yang lama sudah melakukan cara penegakan diagnosa dengan baik dan mengajar kepada yang baru cara melakukan penegakan diagnosa yang baik dan benar sehingga tidak terdapat hubungan diagnosa keperawatan dengan masa kerja perawat.

Masa kerja perawat sangat menentukan kualitas perawat yang ada didalam ruangan. Perawat yang mempunyai masa kerja baru maka pengalaman perawat tersebut masih terbatas dibandingkan dengan perawat yang telah lama berada diruangan tersebut. Masa kerja perawat yang telah lama memiliki kemampuan yang lebih,untuk pendokumentasian asuhan keperawatan yang didapat diruangan 
selama beberapa tahun semenjak bekerja di rumah sakit. Biasanya seseorang yang sudah lama masa kerja pada ruangan maka makin mudah ia memahami tugas dan tanggung jawabnya terhadap pendokumentasian asuhan keperawatan, sehingga memberi peluang orang tersebut untuk meningkatkan pendokumentasian asuhan keperawata, dan tindakan pada pasien serta beradaptasi dengan lingkungan dimana dia berada ${ }^{[25]}$.

\section{Hubungan Faktor Motivasi Perawat dengan Penegakan} Standar Diagnosa Keperawatan di Ruang Rawat Inap RSUD

\section{Soedarso Pontianak}

Perawat yang memiliki motivasi tinggi cenderung rendah untuk mengalami burnout. Dalam pelayanan kesehatan, perawat menghabiskan waktu 24 jam bersama pasien dibanding tenaga kesehatan lainnya. Karena pelayanan kesehatan yang baik adalah bagian integral yang mencakup bio-psiko-sosiospiritual yang ditujukan kepada individu, keluarga, kelompok dan masyarakat $^{[27]}$.
Menurut peneliti motivasi perawat berhubungan dengan penegakan diagnosa keperawatan terlihat dari hasil penelitian bahwa semua perawat soedarso yang mempunyai motivasi tinggi lebih baik dalam melakukan penegakan diagnosa dari pada yang motivasi rendah hanya sedikit saja melakukan penegakan diagnosa yang baik sehingga menyebabkan ada hubungan motivasi dengan penegakan diagnose keperawatan.

Motivasi perawat sangat dibutuh kan dalam pekerjaan perawat karena dengan motivasi yang baik bisa menumbuhkan semangat untuk bekerja, sehingga pekerjaan yang dilakukan akan mendapatkan hasil yang lebih memuaskan. Semakin tinggi motivasi seseorang untuk bekerja maka hasil yang didapat juga akan lebih baik. Motivasi yang tinggi akan memberikan pendokumentasian asuhan keperawatan pada pasien juga akan lebih baik, sehingga bisa memberikan tindakan yang lebih tepat, dan akurat kepada pasien. Jika motivasi seseorang dalam bekerja rendah maka dalam menjalankan pekerjaan seperti pendokumentasian 
asuhan keperawatan akan bekurang, karena kurang nya semangat untuk mengerjakan tindakan tersebut

1.Berdasarkan hasil distribusi responden umur diperoleh umur terbanyak pada rentang 26-35 tahun $(58,4 \%)$. Berdasarkan hasil distribusi responden jenis kelamin diperoleh perempuan sebangai jenis kelamin terbanyak (71,4\%). Berdasarkan hasil distribusi responden tingkat pendidikan diperoleh DIII sebagai jenis pendidikan terbanyak $(76,6 \%)$. Berdasarkan hasil distribusi responden lama bekerja diperoleh hasil terbanyak pada rentang masa kerja $>5$ tahun $(59,7 \%)$. Berdasarkan hasil distribusi status kepegawaian diperoleh hasil terbanyak yaitu perawat PNS $(53,2 \%)$.

2.Motivasi kerja perawat di Ruang Rawat Inap Rumah Sakit Umum Daerah Soedarso Pontianak termasuk dalam kategori tinggi yaitu sebesar $(80,5 \%)$

3.Pelaksanaan penegakan diagnosa keperawatan di Ruang Rawat Inap sehingga tindakan yang diberikan kepada pasien juga akan berkurang $^{\text {[25] }}$

\section{KESIMPULAN}

Rumah Sakit Umum Daerah Soedarso Pontianak Pendidika termasuk dalam kategori tinggi yaitu sebesar $(97,4 \%)$.

4.Tidak terdapat hubungan antara usia perawat dan penegakan standar diagnosa keperawatan di ruang rawat inap RSUD Soedarso Pontianak.

5.Tidak terdapat hubungan antara pendidikan perawat dan penegakan standar diagnosa keperawatan di ruang rawat inap RSUD Soedarso Pontianak.

6.Tidak terdapat hubungan antara masa kerja perawat dan penegakan standar diagnosa keperawatan di ruang rawat inap RSUD Soedarso Pontianak.

7.Terdapat hubungan antara motivasi perawat dan penegakan standar diagnosa keperawatan di ruang rawat inap RSUD Soedarso Pontianak. 


\section{DAFTAR PUSTAKA}

1. Aprisunadi. (2017). Standar Diagnosis Keperawatan Indonesia. Jakarta: Dewan Penggurus Pusat Persatuan Perawat Nasional Indonesia.

2. Hidayah, Nur (2014). Manajemen Model Asuhan Keperawatan Profesional (MAKP) Tim Dalam Peningkatan Kepuasan Pasien Di Rumah Sakit. Jurnal Kesehatan Vol 1. No. 2; 410426

3. Rachmania, D., Nursalam., Yunitasari, E. (2016). Pengembangan instrumen diagnosis \& intervensi keperawatan berbasis standardized nursing language (NANDA, NOC, NIC). Jurnal Ners Vol 11 (2) Hal 157-163.

4. Machfoedz. 2013 Metodologi penelitian (kuantitatif dan kualitatif): Bidang kesehatan, kesehatan, kebidadan, krdokteran (Ed. Rev). Yogyakarta: Fitramaya.

5. Notoatmodjo, S. (2012). Metodologi Penelitian Kesehatan. Jakarta : Rineka Cipta.

6. Dharma, K. K. (2015). Metodelogi Penelitian Keperawatan. Jakarta: Trans Info Media.

7. Depkes RI. (2012). Standar Tenaga Keperawatan di Rumah Sakit, Depkes RI. Jakarta

8. Nursalam, Efendi.,F. (2008) Pendidikan

Dalam

Keperawatan. Jakarta:
9. Dewi, Myta Kirana. (2016). Hubungan Sikap Disiplin Perawat dengan Efektivitas Pelaksanaan Timbang Terima di RSUD dr. abdoer Rahem Situbondo. Skripsi. Tidak dipublikasikan

10. Wahyudi, I. (2010). Hubungan Persepsi Perawat Tentang Persepsi Keperawatan, Kemampuan, Motivasi Kerja Terhadap Kinerja Perawat Pelaksana di RSU dr. Slamet Garut. Tesis. Tidak dipublikasikan.

11. Nugroho, A.D., \& Widodo, A. (2011). Hubungan Motivasi Kerja Perawat dengan Pemberian Pelayanan Keperawatan Kepada Pasien Keluarga Miskin di RSUI Kustati Surakarta. Tidak dipublikasikan

12. Meidian, F. (2012). Analisis Hubungan Faktor-Faktor Motivasi Kerja terhadap Disiplin Kerja Pegawai Non Medis di Gedung Administrasi RS X. Skripsi. Tidak dipublikasikan

13. Yanti, R. I., \& Warsito, B. E. (2013). Hubungan Karakteristik Perawat, Motivasi dan Supervisi dengan Kualitas Dokumentasi proses Asuhan Keperawatan. Jurnal Manajemen Keperawatan. Volume 1, No.2, November 2013; 107114

14. Blais, K. K., Hayes, J. S., Kazier, B. (2012). Praktik Keperawatan Profesional Konsep dan Perspektif Edisi 4. Jakarta : EGC 
15. Mogopa, C. P., Pondaag, L., \& Hamel, R. S. (2017). Hubungan Penerapan Metode Tim dengan Kinerja Perawat Pelaksana di Irina C RSUP Prof. Dr. R. D. Kandou Manado. E-Journal Keperawatan (e-Kp) Vol 5 (1) 16. Pribadi, $\mathrm{T} \&$ Prawesti, D. (2012). Kepuasan pasien terhadap kinerja oerawat kontrak dan perawat tetap. Jurnal STIKES RS Baptis Kediri.

17. Asmadi. (2008) Konsep dasar keperawatan. Jakarta: Buku kedokteran EGC.

18. Patingtingan, Y. M., Patingringgi, S.A., \& Anggraini, R. (2013). Gambaran Motivasi Kerja Perawat di Ruang Rawat InapRS Universitas Hasanudin Makasar. Tidak dipublikasikan

19. Oktafiyani, Y. (2009). Pengaruh Pendidikan dan Masa Kerja Terhadap Kedisiplinan Karyawan di SMK Muhamadiyah Surakarta. Skripsi. Tidak dipublikasikan.

20. Asmuji. (2016). Manajemen Keperawatan : Konsep dan Aplikasi. Yogyakarta : ArRuzz Media.

21. Riskah, K (2017) Hubungan Motivasi Kerja Perawat Terhadap Pelaksanaan Timbang Terima Keperawatan di RSUP. Pontianak. Skripsi Dipublikasikan

22. Ulum, Muh. Miftahul dan Wulandari, Ratna D. (2013). Faktor yang Mempengaruhi
Kepatuhan

Pendokumentasian Asuhan Keperawatan Berdasarkan Teori Kepatuhan Milgram. Jurnal Administrasi Kesehatan Indonesia,Vol. 1(3), 252-262

23. Marquis, B. L. \& Huston, C. J. (2010). Kepemimpinan dan Manajemen Keperawatan Edisi 4 Teori dan Aplikasi. Jakarta : EGC

24. Zenah, S. N. (2014). Hubungan Pemberian Insentif dengan Motivasi Kerja Perawat Ruang Rawat Inap Kelas III RSUD Inche Abdul Moeis Samarinda. eJournal Administrasi Negara,3 (2): 451-463

25. Amelia, E, Herawat, L, Nofriadi. (2018) Faktorfaktor kelengkapan pendokmentasian asuhan keperawatan di instalasi rawat inap RSUD Lubuk Sikaping. Jurnal documentation of , nurses. Vol 1 No 1 Hal 2622-2256.

26. Robbins, Stephen P. dan Coulter, Mary. (2010). Manajemen Edisi 10 Jilid 2. Jakarta : Erlangga

27. Tawale, E. N. Budi, W. \& Nurcholis, G. (2011, agustus). Hubungan antara Motivasi Kerja Perawat dengan Kecenderungan mengalami Burnout pada Perawat di RSUD SeruiPapua. INSAN, 13(2), 74-84. 